University of Pennsylvania Carey Law School

Penn Law: Legal Scholarship Repository

Faculty Scholarship at Penn Law

6-13-2017

\title{
The Effect of Health Insurance Coverage Expansions on Auto Liability Claims and Costs
}

\author{
Srikanth Kadiyala \\ RAND Corporation \\ Paul Heaton \\ University of Pennsylvania Carey Law School
}

Follow this and additional works at: https://scholarship.law.upenn.edu/faculty_scholarship

Part of the Health Law and Policy Commons, and the Insurance Commons

\section{Repository Citation}

Kadiyala, Srikanth and Heaton, Paul, "The Effect of Health Insurance Coverage Expansions on Auto Liability Claims and Costs" (2017). Faculty Scholarship at Penn Law. 1956.

https://scholarship.law.upenn.edu/faculty_scholarship/1956

This Article is brought to you for free and open access by Penn Law: Legal Scholarship Repository. It has been accepted for inclusion in Faculty Scholarship at Penn Law by an authorized administrator of Penn Law: Legal Scholarship Repository. For more information, please contact PennlawIR@law.upenn.edu. 


\section{The Effect of Health Insurance Coverage Expansions on Auto Liability Claims and Costs}

Srikanth Kadiyala and Paul Heaton

RAND Justice, Infrastructure, and Environment/Institute for Civil Justice

WR-1214

June 2017

RAND working papers are intended to share researchers' latest findings and to solicit informal peer review. They have been approved for circulation by RAND Justice, Infrastructure, and Environment but have not been formally edited or peer reviewed. Unless otherwise indicated, working papers can be quoted and cited without permission of the author, provided the source is clearly referred to as a working paper. RAND's publications do not necessarily reflect the opinions of its research clients and sponsors. RAND ${ }^{\circledR}$ is a registered trademark. 
For more information on this publication, visit www.rand.org/pubs/working_papers/WR1214.html

Published by the RAND Corporation, Santa Monica, Calif.

C Copyright 2017 RAND Corporation

RAND $^{\circledR}$ is a registered trademark

\section{Limited Print and Electronic Distribution Rights}

This document and trademark(s) contained herein are protected by law. This representation of RAND intellectual property is provided for noncommercial use only. Unauthorized posting of this publication online is prohibited. Permission is given to duplicate this document for personal use only, as long as it is unaltered and complete. Permission is required from RAND to reproduce, or reuse in another form, any of its research documents for commercial use. For information on reprint and linking permissions, please visit www.rand.org/pubs/permissions.html.

The RAND Corporation is a research organization that develops solutions to public policy challenges to help make communities throughout the world safer and more secure, healthier and more prosperous. RAND is nonprofit, nonpartisan, and committed to the public interest.

RAND's publications do not necessarily reflect the opinions of its research clients and sponsors.

Support RAND

Make a tax-deductible charitable contribution at

www.rand.org/giving/contribute

www.rand.org 


\title{
The Effect of Health Insurance Coverage Expansions on Auto Liability Claims and Costs
}

\author{
Srikanth Kadiyala \\ RAND \\ Paul Heaton \\ University of Pennsylvania and RAND
}

June 2017

\begin{abstract}
How do the Affordable Care Act health insurance coverage expansions affect payment for medical care provided through liability insurance, such as auto insurance? Theoretically, expanding coverage might lead to a substitution of health insurance disbursements for automobile insurance disbursements. Alternatively, expanding health insurance coverage might increase utilization of medical care, increasing auto liability claims payments. The net effect of these two mechanisms can only be determined empirically. We evaluate the health insurance-auto insurance interaction by examining the 2010 ACA dependent coverage expansion. Prior to 2010, individuals 19 and older were excluded from health insurance coverage under their parental health insurance plan. In September 2010, as part of the ACA, individuals were allowed to continue health insurance coverage until age 26 . We use this policy change and claims data from insurers representing approximately $60 \%$ of the automobile passenger market to evaluate the effects of expanding health insurance coverage on auto liability claim payments. Using a difference-in-difference research design, we find an approximate $10 \%$ reduction in the total $\mathrm{BI}$ claim count in the policy-affected 19-25 ages when compared to the control group of individuals 26-34. Conditional on filing a claim, we also find an approximate $9 \%$ reduction in the mean total auto insurance paid amount in the 19-25 ages compared to the 26-34 ages. We do not identify any effects of the policy on the PIP auto insurance line.
\end{abstract}

\footnotetext{
We gratefully acknowledge financial support from the Casualty and Actuarial Society (CAS) and the RAND Institute for Civil Justice. We thank the Insurance Research Council for providing assistance in understanding the closed claims data, and David Auerbach, Michael DeMattei, Glen Leibowitz, Anne Petrides, and participants in the 2016 CAS Annual Meeting for providing helpful comments on this research. All statements and conclusions in the paper are the sole responsibility of the authors and not the aforementioned individuals or institutions.
} 


\section{Introduction}

Prior to the implementation of the Affordable Care Act (ACA), approximately $85 \%$ of the adult population was insured. Over the 2010 to 2015 time period, over 19 million individuals have gained access to health insurance, either via the 2010 ACA dependent coverage expansion, state and federal health insurance exchanges, or increases in coverage via Medicaid (Garrett and Gangopadhyaya, 2016). The effects of the coverage expansions on the U.S. population and other participants in the health care system are likely to be substantial. Increases in health insurance coverage will likely increase financial risk protection and health care utilization among enrollees, and lead to an increase in total reimbursements for physicians and hospitals.

Although political debates over the ACA have focused primarily on its impacts on the health insurance market, it seems plausible that the ACA may have implications for many other insurance products because many other forms of insurance provide compensation for medical care. In this paper, we assess whether health insurance expansions under the ACA affect claim payments made through the auto liability insurance system. In 2007, several years prior to the implementation of the ACA, auto insurers paid for $\$ 35$ billion in medical expenditures or two percent of U.S. health care costs, a figure comparable to disbursements in the medical malpractice liability system. As we describe in greater detail in the text, in some situations, health insurance may serve as a substitute for auto liability, in which case an increase in health insurance coverage potentially reduces auto insurers claim payments. However, other forces may lead to coverage expansions increasing health care payments borne by auto insurers.

We explore the relationship between the health and auto insurance markets by analyzing the effects of the 2010 ACA dependent coverage health insurance expansion 
on auto liability claim patterns. Prior evaluations of this policy change find that health insurance coverage increased by approximately 6 percentage points among those aged 19-25 as compared to a control group of individuals 26 and older (Sommers et al. 2013), a result we confirm in our own analysis of data from the American Community Survey (ACS). Comparing samples of closed auto insurance claims from 2007 and 2012 and a differences-in-difference research design, we show measurable reductions in medical damages and resultant claim payments among individuals ages 19-25 compared to individuals ages 26 and above after the dependent coverage expansion. Supplementary analyses suggest that reductions in emergency room physician payments represent an important channel for the observed decrease in claim costs.

The paper proceeds as follows: in section II, we describe the various mechanisms by which increases in health insurance coverage might affect auto insurance disbursements. In section III, we replicate and expand on the existing empirical work regarding the effects of the ACA dependent coverage expansion on health insurance coverage among young adults. In section IV, we describe the data and the empirical methodology used to estimate the effect of the ACA on auto claim frequency and severity. In section $\mathrm{V}$, we present our main results using data from the 2007 and 2012 auto insurance claims databases, enrich our findings using physician and hospital utilization and charge data, and conduct several analyses aimed at testing the sensitivity of the initial results to alternative regression models and sample selection procedures. We conclude with a discussion of the applicability of these results to the ACA health insurance expansions that began in early 2014. 


\section{Auto Insurance and Health Insurance}

Auto insurance in the United States generally covers not only vehicle damage, but also damages due to injury in a crash, such as medical treatment, lost wages, and payments for pain and suffering. Liability insurance, the focus of this study, is the component of auto insurance that provides compensation for injuries and depending on the type of policy, can provide payments for both third-party (i.e. inflicted by the insured on others) or first-party (i.e. injuries of the insured, regardless of fault) damages. In this paper, we focus on Bodily Injury (BI) and Personal Injury Protection (PIP) coverages, which account for the largest fraction of auto insurance medical payments. ${ }^{1} \mathrm{BI}$ is the most common form of auto liability insurance, and is required in nearly all states. It pays for damages, including medical care, that are the fault of the insured party. PIP pays for medical care, lost wages, and selected other economic damages for the insured party regardless of fault, and is a required coverage in 12 states, including Florida and New York.

There are several channels through which the health insurance status of an individual involved in an auto crash might influence the ultimate payments made by liability insurers. For $\mathrm{BI}$, if the injured individual does not have health insurance, they may have more incentive to press a bodily injury claim as a means of seeking recovery for medical expenses than if their costs were already covered through health insurance. Additionally, the presence or absence of health insurance may impact the rates at which

\footnotetext{
${ }^{1}$ The other main coverages are Underinsured/Uninsured Motorist (UM/UIM), which is a first-party coverage that functions like $\mathrm{BI}$ in the event that the responsible party in an accident failed to maintain adequate liability insurance, and Med Pay, which is an optional coverage offered in states without PIP that covers medical costs for the insured party. Because a comparatively small proportion of accidents involve uninsured drivers, and because Med Pay policy limits tend to be low and Med Pay is only purchased by some drivers, these coverages are relatively less important as sources of payments for auto injuries.
} 
providers accept payments for medical care, which can ultimately feed into the auto claim settlement amount. Because health insurers often negotiate preferred reimbursement rates that are substantially below the rates charged to the uninsured, patients with health insurance may be allowed lower payment rates even when auto insurers ultimately bear the costs of treatment. ${ }^{2}$

PIP coverage functions somewhat differently from $\mathrm{BI}$, and therefore is not impacted in the same way by the health insurance coverage status of the insured. PIP is a first-party coverage that makes payments regardless of fault, and is generally the primary payer in an injury situation. Moreover, because PIP generally reimburses at much higher rates than health insurance, providers have strong incentives to seek reimbursement for PIP over health insurance. For PIP, then, health insurance is less likely to act as a direct substitute for payments.

For both PIP and $\mathrm{BI}$, however, there are additional potential channels linking health insurance and claim payments. When an individual does not have health insurance, auto insurance at the time of an accident may in some cases be used to provide reimbursement for pre-existing conditions unrelated to the accident. ${ }^{3}$ Informal conversations with auto insurance experts suggest such substitution is possible, although empirical studies that have evaluated the magnitudes of such substitutions are lacking. Heath insurance expansions, to the extent that they permit individuals to

\footnotetext{
${ }^{2}$ One reason for this phenomenon is that liability payments depend on a determination of fault, and fault is not always clear at the time a patient presents for medical care. Thus, in many cases providers will initially accept a patient under the supposition that their care will be covered through their health insurance, and auto insurance may not step in until after the care has been received and billed. In such cases health insurers can recover their expenses through a process called subrogation, which we do not explore here.

${ }^{3}$ An example might be an uninsured individual with chronic back pain who is involved in an auto accident and then receives chiropractic treatment.
} 
address pre-existing health issues through their new insurance, might decrease future auto liability payments.

A second possible sub-mechanism, involves treatment increases due to better insurance coverage. Doyle (2005) finds that auto accident victims who had health insurance received approximately $20 \%$ more treatment than auto accident victims who did not have health insurance. If physicians provide more treatment to insured individuals, it's possible that some portion of these additional treatment costs will be passed on to auto insurers.

The above discussion identifies potential mechanisms through which coverage expansions might both increase and decrease auto claim frequency and or severity. There are plausible reasons to expect that $\mathrm{BI}$ might be more dramatically impacted than PIP, but ultimately the extent and direction of any impacts is an empirical question. We turn next to addressing that question, focusing on a large coverage expansion that offers a credible means of separating the effects of health insurance from other confounding factors that determine claim frequency and severity.

\section{The ACA Dependent Coverage Expansion}

One of the first provisions of the Affordable Care Act to take effect was an expansion of health insurance coverage for young adults up to 26 years of age whose parents have employer-sponsored or individual health insurance. ${ }^{4}$ This provision applied to all new health insurance contracts starting on or after September 23, 2010as of that date, adult children, regardless of residence, student status, or marital status,

\footnotetext{
${ }^{4}$ This provision was not subject to meaningful court challenges and thus there was little uncertainty regarding implementation.
} 
became eligible for insurance under their parents' health plan (U.S. Department of Labor, 2013). This eligibility under their parents' health plan was extended to young adults regardless of whether they were eligible for insurance through another employer or through a state health exchange. Prior to the dependent coverage expansion, young adults were the age group least likely to be covered by health insurance (Collins, Robertson, Garber, \& Doty, 2013) and had the lowest level of access to employmentbased insurance (U.S. Department of Labor, 2013). ${ }^{5}$

Prior research concludes that the 2010 ACA measure increased health insurance coverage among young adults. Data from the 2010 and 2011 National Health Insurance Surveys revealed a 5.5 percentage point increase in health insurance coverage for the 19-25 age group and no change in health insurance coverage for the 26-34 age group (Sommers et al. 2013). Before using auto insurance claims data to understand the effects of the coverage expansions on auto insurance disbursements, we first replicate these initial results using data from the 2008 and 2013 American Community Survey (ACS). The ACS data is available yearly from the United States and to our knowledge, contains the largest samples from which to examine health insurance trends in the United States ${ }^{6}$. The ACS data began to collect health insurance information starting in 2008 , so we use the 5-year 2008-2013 data window to replicate prior analyses. Figure I presents the share of individuals who are covered by health insurance by single year of age in the pre (2008) and post (2013) ACA dependent

\footnotetext{
${ }^{5}$ Some states had implemented similar coverage expansions prior to the ACA. Monheit et al. (2011) provides a more detailed discussion.

${ }^{6}$ The Behavioral Risk Factor Social Survey (BRFSS) data is another possible data source to analyze health insurance trends in the United States and has been used previously by researchers to understand the effects of the dependent coverage expansion. The sample sizes in the ACS data are substantially larger than the sample sizes in the BRFSS data.
} 
coverage expansion time periods. ${ }^{7}$ Figure I shows a notable increase in the share of individuals covered by health insurance (approximately 5 percentage points) in the under 26 population over the 2008 to 2013 time period. Health insurance coverage for individuals aged 26 and over is nearly identical in the pre and post policy years. Consistent with prior findings, in a difference-in-difference regression framework, we find that health insurance coverage increased by 5.7 percentage points in the under 26 ages across the pre and post policy time periods. Using the share of individuals covered by health insurance in the $19-25$ age group in 2008 as the base (69\%), the estimated change in coverage translates to an $8.3 \%$ increase in the health insurance coverage for the $19-25$ age group.

\section{Data and Empirical Methods}

Our primary data sources are the auto insurance closed claims databases from 2007 and 2012 produced by the Insurance Research Council (IRC). In each year, the IRC samples claims from U.S. auto insurers who collectively represent approximately 60 percent of the US private passenger auto insurance market. Participating insurers abstract all paid claims closed within a pre-determined time window (typically around two weeks) using a common abstraction procedure developed by the IRC. Although it is possible that these data are not perfectly representative of the overall auto insurance market, due both to non-participation by some insurers and possible seasonality in claims, the IRC data are widely viewed as the best source of auto claims micro-data spanning multiple companies. Moreover, there is little reason to suspect that any non-

\footnotetext{
${ }^{7}$ The public use ACS data does not reveal information about the date of interview. Since the ACA dependent coverage policy went into effect in October, the error due to misclassification should be minor and lead to conservative estimates of health insurance effects.
} 
representativeness that might arise due to the IRC's sampling procedures would differentially affect claims involving people of particular ages. The databases contain information on all auto liability coverages, but we focus our analysis on $\mathrm{BI}$ and PIP.

The IRC auto claims data contains information on the age of the claimant, whether the accident was covered under PIP or BI, the accident year, and, when available, medical damages (in dollars) filed by the claimant and any outlays from the insurers $^{8}$. The data also contains detailed information on claimant demographics, accident characteristics, injury severity (including the type of injury and the body part that was injured), and the types and amounts of medical care received. All records include the total amount paid to settle the claim; for those claims where the insurer has partitioned the payments into components for medical care, other economic losses, pain and suffering, etc., the amounts of these payments are also recorded.

\section{Empirical Methods}

We conduct two sets of analyses with the claims data, and estimate our models separately for $\mathrm{BI}$ and PIP. In the first set of analyses, we examine claim counts by age, our measure of claim frequency, to test whether the coverage expansion affected the auto liability claim volume. More specifically, using a differences-in-difference approach, we test to see if the total number of claims in the under 26 ages compared to the over 26 group increased or decreased following the policy change. In the second set of analyses, the severity analyses, we test whether the policy change affected the

\footnotetext{
${ }^{8}$ When filing a claim, most but not all claimants allocate damages to different categories-e.g. damages for medical services, lost wages, etc.
} 
reported damages and payment amounts-our measures of claim severity--in the under 26 group when compared to the over 26 group across the two time periods. We conduct the total claims analyses using Poisson regression analyses of counts measured at the state, age, and year level of observation, weighting the cells by stageyear-age population obtained from the U.S. Census Bureau population. For the analyses involving the claimed damage and actual disbursement amounts, we conduct the analyses at the individual claim level. For these latter analyses, we utilize ordinary least squares, after taking logs of the dependent variables to minimize the effects of outliers.

We use the following regression specification to identify the effect of the policy change on $\mathrm{BI}$ and PIP claim counts and severity:

$$
Y_{i}=\beta_{1}+\beta_{2} \text { Age }+\beta_{3} \text { Under_26 }+\beta_{4} \text { Post_Policy }+\beta_{5}(\text { Under_ } 26 * \text { Post_Policy })+\gamma Z_{i}+\varepsilon_{i}
$$

In the regression equation Under_26 is a dummy variable for whether the observation is from the 25 and under ages, Post_Policy is a dummy variable for whether the observation is from a year in which the ACA dependent coverage expansion is in effect and $Z_{i}$ is a vector of additional covariates that always includes state, year, and stateyear interactions. The $\beta_{5}$ coefficient captures the main coefficient of interest, the percentage change $\left(100^{*}\left(\exp \left(\beta_{5}\right)-1\right)\right.$ in the treated group (ages under 26$)$ as compared to the percentage change in auto disbursements in the control group (ages 26 and over).

As stated, the dependent $Y_{i}$ variables here include claim counts, damages and paid amounts. In some specifications, we separately consider medical damages and 
medical payments as distinct from total damages and total payments. The medical damage amount captures the claimant's reported outlays for medical care. The medical paid amount captures the portion of the overall payment allocated by the insurer to compensate for medical payments, and the total paid amount captures the total payment from the auto insurer, including medical, lost wages, and other damages. ${ }^{9}$

In the simplest regression specification for equation (1), we include dummy variables for age, year-fixed effects, state-fixed effects, state-year fixed effects, and an interaction term between the post policy dummy variable and the dummy variable for being in the treated age group. The year-fixed effects account for macroeconomic and technological change that affects all states and age groups, while the state/year interactions account flexibly for unobserved state-level factors-for example, changes to state tort law or traffic laws-that affect individuals of all ages. We also test the sensitivity of these estimates to any potential differential time trends across the two age groups in the outcomes. If the outcomes are trending differentially across the two age groups due to uncontrolled factors, failing to account for differential trends will bias the main coefficient of interest.

The auto insurance data collects information on more than 20 types of injuries, injury severity, information on whether the accident led to a disability and the severity of the impact. In addition to adjusting for accident and injury severity, we also examine regression models that adjust for any other claimant or policy related characteristics that might have an effect on the reported damages and amount of payment. These include

\footnotetext{
${ }^{9}$ Although the medical paid amount ideally captures the insurer disbursement for medical expenses, in approximately $25 \%$ of the claims insurers do not report the medical paid amount. In these cases, the insurer likely did not apportion liability uniquely among medical, lost wages and other categories of losses.
} 
information on the sex of the claimant, the location of the claimant, whether the claimant is employed, the number of vehicles involved in the accident, determination of fault and insurance policy limits. Finally, for the claim counts analyses, using data from the American Community Survey, we also test the sensitivity of the main estimates to the inclusion of controls capturing any differential changes in education, employment, average wages, marital status and vehicle ownership among the state, age and time cells. Since regressions with state and state-time interactions are data intensive, we first examine results using the larger age windows considered previously in the literature, 19-34. We then test the sensitivity of these estimates to using a narrower age band of ages 23-28 (Barbesco, Courtemanche and Qi 2014).

\section{Results}

\section{Graphical Analyses}

We begin with graphical analyses of changes in total $\mathrm{BI}$ and PIP claim counts, medical damages and medical paid amounts over the 2007 to 2012 time period. Figures II and III plot percentage changes in total claims over the 2007 and 2012 time period for $\mathrm{BI}$ and PIP coverage lines by age of the claimant. Figures IV-VI plot changes in mean (per claim) BI medical damage, BI medical paid, and BI total paid amounts over the 2007 and 2012 data years. Figures VII-IX replicate the same figures using data from the PIP coverage line. Because of changes in the sampling scheme and price inflation, we would not expect claim volume or payment amounts to be constant across years; however, the figures reveal the extent to which the age groups specifically 
targeted by the ACA young adult expansion appear to experience different trajectories in outcomes as compared to similar, unaffected ages.

An examination of the data from Figures II-VII reveals several interesting findings. First, the percent change in $\mathrm{BI}$ claims, and the percent changes in mean $\mathrm{BI}$ medical damages and mean BI medical paid amounts, are consistently smaller in the 19-25 ages over the 2007 to 2012 time period when compared to the $26-34$ ages. Most striking, the claim counts per age within the $19-25$ age group decreased by $7.8 \%$ compared to a $6.6 \%$ increase in the $26-34$ ages. Conditional on submitting a claim, the mean $\mathrm{BI}$ medical damage amount in the $19-25$ ages increased on average by $7.6 \%$; this compares to a $28.5 \%$ average increase in the $\mathrm{BI}$ medical damage amount in the $26-34$ ages. Similarly, conditional on submitting a claim, the mean $\mathrm{BI}$ medical paid amount in the $19-25$ ages increased on average by $4.3 \%$. This compares to an average $11.6 \%$ increase in the medical damage amount in the 26-34 ages. The unadjusted changes in BI total paid amounts in the 19-25 group are also generally smaller when compared to the changes in the 26-34 ages, except for an outlier value at age 24 .

Also noticeable directly from the figures, the differences in claim counts, damages, and payments among the groups with expanded health insurance coverage are observable even when narrowing attention to those aged 23-28. For example, limiting the sample to just the $23-25$ ages indicates an average $9.2 \%$ decrease in claim counts over the 2007-2012 time period, compared to no change in the 26-28 ages.

Compared to $\mathrm{BI}$, we observe different patterns in PIP closed claim counts across the two age groups over the 2007-2012 time period. For PIP coverage, we do not observe any differential changes in claim counts across the $19-25$ vs. the $26-34$ ages. 
Although there is a noticeable drop in claim counts over the two time periods, this drop occurs in near equal amounts in both age groups. Unadjusted mean PIP medical damages and medical paid amounts exhibit similar age-time patterns as the BI medical damages and BI medical paid amounts. Taking the PIP medical damage amount as an example, we calculate an average $13 \%$ increase within the $19-25$ ages over the 2007 to 2012 time period. This compares to an average $47 \%$ increase in the $26-34$ ages.

\section{Regression Results}

\section{Bodily Injury Results}

In Tables I-III, using equation 1, via regression analyses, we examine the effects of the policy change on the total number of $\mathrm{BI}$ and PIP claims (Table I), BI medical damages, $\mathrm{BI}$ medical paid and $\mathrm{BI}$ total paid amounts (Table II), and PIP medical damages, PIP medical paid and PIP total paid amounts (Table III). In each of these tables, column one contains results for our primary coefficient of interest from the simplest regression specification. In the remaining columns, we report the primary coefficient of interest from regression models where we add the injury severity, demographic and auto insurance policy covariates as controls.

For $\mathrm{BI}$, we find moderate effects of the dependent coverage expansion on total closed claims (Table I), and total paid amounts (Tables II). For the BI total claims analyses (Table I, column I), we find an $11.8 \%{ }^{10}$ reduction in total claims in the under 25 group compared to the over 25 group, and this effect is statistically significant at the $1 \%$

\footnotetext{
${ }^{10}$ As described in the methods section all of the coefficients reported in the tables must be evaluated using the following formula, $\left(100^{*}(\exp (\beta)-1)\right.$ to be understood as percentage changes. In this instance, using the coefficient in Table I (-.126) and evaluating using the reported formula, results in a value of $11.8 \%$.
} 
level. Adjusting for state-year level education, employment, wage and marital status covariates only marginally reduces the estimated effect to $10.1 \%$ (Table I column II).

Table II shows similar effects of the policy change on measures of claim severity, particularly the total payment, which is reported for all closed auto insurance claims. In the simplest specification, (Table II, column 1), we find an approximate seven percent reduction in total disbursement in the 19-25 group compared to the 26-34 age group and this estimate is statistically significant at the $10 \%$ level. Adjusting for the injury and accident severity variables increases this estimate slightly to $8.6 \%{ }^{11}$ and this estimate is statistically significant at the five percent level. Adding additional controls related to claimant and policy characteristics only marginally affects this coefficient and has no effect on statistical significance. For the medical damages and medical paid amount analyses, we do not identify any strong effects of the policy change. Although we consistently find negative effects for the 19-25 age group with respect to medical damages, none of the coefficients are statistically significant at the five or $10 \%$ level.

It is important to recognize that because it is conducted at the level of the individual claim, the above analysis of claim severity incorporates two effects-a selection effect arising due to a change in the pool of claims observed within the liability system as a result of the reform, plus any direct effect of the reform on claim severity. A direct effect might occur if, for example, collateral sources of payment are taken into account in calculating a personal injury award, so that the presence of payments from a health insurer partially offsets payments that pre-reform would have been made by the

\footnotetext{
${ }^{11}$ In this instance using the coefficient reported in Table II column II (-.090), and evaluating using the reported formula, $\left(100^{\star}(\exp (\beta)-1)\right.$, results in a value of $8.6 \%$.
} 
$\mathrm{BI}$ insurer. The results in the tables do not enable us to cleanly separate out these two effects.

One seemingly plausible scenario that does not seem particularly consistent with these results, however, is one in which gaining health insurance has no direct effect on claim severity, but does result in a shifting of lower severity, and conceivably more "elective" claims out of the liability system and into the health insurance system. Under such a scenario, we would expect claims of lower than average value to disappear from the sample post-reform, in which case the average damage amount or payment would rise. The results here appear to contradict such a scenario.

\section{PIP Results}

Next, we examine the effects of the dependent coverage expansion on the PIP auto insurance line. As noted previously, unlike BI, we do not expect health insurance coverage and PIP coverage to interact in a significant way and therefore expect effects for PIP coverage that are below any $\mathrm{BI}$ effects.

In Table I we replicate the regression models for PIP claim counts, and in Table III we replicate the regression models for the PIP medical damage amount, the PIP medical paid amount, and the PIP total paid amount variables. Unlike for $\mathrm{BI}$, we do not find any differential decreases in PIP claim counts for the 19-25 ages compared to the 26-34 ages. In the simplest analyses, we estimate a near zero effect of the policy change on PIP claim volume (coefficient of .006). Adding covariates to the regression model results in a positive coefficient, but this coefficient is not statistically significant even at the $10 \%$ level. With respect to the medical damage, medical paid and total paid 
variables (Table III), we consistently find much smaller point estimates for PIP damages and PIP disbursements when compared to $\mathrm{BI}$ and in none of the cases are the estimates statistically significant at the five or even the $10 \%$ level.

\section{Robustness Checks}

In the initial analyses, to maximize the sample size, we used data from the larger agewindow to understand the effects of the coverage expansion. Increasing the sample size in this manner could in theory, bias the main coefficients of interest as individuals who are farther away in age do not provide a good counterfactual for the claims experience of young adults affected by the ACA. We tested the sensitivity of the $\mathrm{BI}$ estimates to the age window selection criteria by re-estimating the claim count, the medical damages, medical paid and total paid regression models but now only using the 23-28 ages in the analyses (Tables IV-V). In the narrower age analyses, we continue to find that the dependent coverage expansion reduced claim counts (Table IV) and total paid amounts (Table $\mathrm{V}$ ) for the $23-25$ group compared to the $26-28$ age group. For $\mathrm{BI}$, in the smaller age bandwidth, we continue to find an approximate $11 \%$ reduction in total claims and this estimate is statistically significant at the $1 \%$ level ${ }^{12}$. We also continue to see reductions in total per-claim reimbursement in the policy affected age groups. In the regression specification that includes controls for accident severity, injury severity, claimant and policy characteristics we find an approximate $15 \%$ reduction in the total paid amount for the 19-25 group compared to the 26-34 age group; this coefficient is

\footnotetext{
${ }^{12}$ Cameron, Miller and Gelbach (2008) find that in analyses with a small number of clusters $(\sim<10)$ clustering on age leads to standard errors that are too small. They suggest using a larger rejection threshold based on clusters- 2 degrees of freedom. We use this larger threshold (T statisticl>2.78) for rejecting the null hypothesis for the analyses that limit the samples to the $23-28$ ages.
} 
statistically significant at the $5 \%$ level. Similar to the larger age group analyses we again, consistently find negative coefficients for the medical damages and medical paid variables, but statistical significance is only reached typically at the $10 \%$ level. Overall, in a comparison of these estimates to estimates from Tables I and II, we consistently find similar or larger point estimates for the main coefficients of interest in the $\mathrm{BI}$ auto insurance line. Finally, in Tables IV and VI, we replicated all of the prior PIP analyses for the narrower ages. Consistent with the larger age group analyses, we do not see any effects of the policy change on PIP claim counts or on per-claim-reimbursement in the PIP auto-insurance line.

\section{Understanding the Estimated BI Effects}

We explore the initial results regarding $\mathrm{BI}$ total paid amounts by analyzing the detailed medical charge information included in the auto insurance claims data. The available charge information is broken down by the type of physician (anesthesiologist, chiropractor, etc.) that provided care, care setting (hospital, outpatient, ER) and the types of tests (MRIs, cat-scans etc.) received by the claimant. From the large set of available variables, we examined the effects of the policy change on mean hospital charges, three physician charge variables (emergency physician charges, general practitioner charges, chiropractor charges) and charges for X-rays. We chose these particular variables since hospital reimbursement is a substantial part of total medical spending and because a large number of claims reported the charge amounts for these variables. 
Table IX presents the results for these analyses, for the two age bandwidths (1934 and 23-38) for regressions where we include the full set of covariates. We do not find any statistically significant changes of the policy on hospital charges or charges for expensive tests, but we do find some suggestive evidence of effects of the policy change on physician charges, particularly ER physician charges. Estimates from the regression models indicate a $17 \%$ reduction in ER physician charges in the $23-25$ group compared to the $26-28$ age group.

\section{Discussion}

How are health insurance and auto insurance markets related? We tested for the interdependencies of these two markets via an examination of the effects of the ACA dependent coverage expansion on auto insurance disbursements in the $\mathrm{BI}$ and PIP coverage lines. We find that increases in health insurance coverage reduce $\mathrm{BI}$ total closed claims and reduce $\mathrm{BI}$ total paid amounts, but do not have effects on the PIP coverage line. $\mathrm{BI}$ auto insurance claims frequency was reduced by approximately $10 \%$ and the mean total liability payment fell by approximately nine percent among young adults exposed to the coverage expansion. Results for BI claim counts and BI total paid amounts are also robust to adjustments that limit the sample to a narrower age band (23-28). We do not find any effects of the 2010 dependent coverage expansion on any of the PIP auto insurance variables (claim counts, medical damages, medical paid and total paid amounts).

What explains the effects identified in this paper? An examination of a breakdown of charges related to different health care services suggests that changes in 
ER physician expenditures contribute significantly to understanding the $\mathrm{BI}$ total paid results. Furthermore, as noted previously auto insurers are also more likely to pay list prices (charges) compared to traditional health insurers. Thus, any substitution away overall, or substitution away particularly from within an expensive product line, from auto insurers to health insurers would result in substantial reductions in auto insurance disbursements.

Since the implementation of the ACA dependent coverage expansion, several other ACA-related health insurance expansions have been implemented, most notably Medicaid expansions; expansions via the private health insurance exchanges. These expansions are significantly larger than the dependent coverage expansion since they are aimed at more than just the 19-25 ages and are supported both by a relaxation of Medicaid eligibility rules as well as significant subsidies for the purchase of private health insurance. What are the implications of the results presented in this paper for the more recent health insurance expansions?

If the parameter estimates identified in the above analyses apply to the insurance expansions in the older ages then we would predict substantial reductions in $\mathrm{BI}$ auto insurance disbursements in the market as a whole. The extent to which these parameter estimates are applicable to a broader set of age groups, though, is unknown. For example, according a 2008 report by the National Research Council, Institute of Medicine and Transportation Research Board, young adults are at the highest risk of serious morbidity from auto accidents (NRC, IOM, TRB, 2007). The prevalence of higher morbidity rates in this age group, and thus the necessity of medical care during the treatment and recovery process, means it is possible that the parameter estimates 
from Tables II-III, which are applicable to a much larger set of people, are potentially upper bounds.

Additionally, the generosity of health insurance provided through the other coverage expansion components of the ACA is likely to differ from that of the young adult expansion. The young adult expansion increased eligibility for existing parental coverage, meaning that the newly insured primarily gained access to employersponsored private health insurance. The ACA Medicaid expansions offered public insurance to some uninsured, but typically featured narrower access to physicians and lower provider reimbursements for services than private health insurance. The exchange-based plans, in contrast, are private plans with fairly generous provider reimbursements, but with higher copays or more limited networks to constrain costs. The varying levels of access and generosity across these different types of health insurance create claiming incentives for patients and providers that may differ from those produced by the young adult expansion. Thus, while these estimates are important in providing some of the first rigorous evidence of a spillover effect from health insurance markets to auto liability insurance, their applicability to the full suite of ACA-related coverage expansions remains uncertain.

\section{Conclusion}

How are health insurance and auto insurance markets related? To our knowledge, this is one of the first studies to examine the effects of health insurance on auto liability payments. Exploiting a health coverage reform (the ACA young adult expansion) that expanded health insurance among an identifiable population in a 
manner unlikely to be related to their underlying propensity to be injured in auto crashes, we show that an increase in health insurance coverage generates measurable reductions in the total number of $\mathrm{BI}$ claims and average $\mathrm{BI}$ payments. Analyses from charge data suggest that a reduction in ER physician spending is a potentially important contributor to the decline in claim severity. We observe no measurable impact of health coverage expansion on the total number of PIP claims or severity. Future work should explore the effects of the more recent, larger, ACA health insurance expansions on auto insurance markets. 


\section{References}

Barbaresco, Silvia \& Courtemanche, Charles J. \& Qi, Yanling. Impacts of the Affordable Care Act dependent coverage provision on health-related outcomes of young adults. Journal of Health Economics. 2015; vol. 40(C): 54-68.

Cameron C, Gelbach J, Miller DL. Bootstrap-Based Improvements for Inference with Clustered Errors. Review of Economics and Statistics. 2008; 90: 414-427.

Collins SR, Robertson R, Garber T, Doty MM. Insuring the future: current trends in health coverage and the effects of implementing the Affordable Care Act. The Commonwealth Fund. 2013. http://www.commonwealthfund.org/Publications/FundReports/2013/Apr/Insuring-the-Future.aspx

Doyle JJ. Health Insurance, Treatment and Outcomes: Using Auto Accidents as Health Shocks. Review of Economics and Statistics. 2005; 87(2): 256-270.

Garret B, Gangopadhyaya A. Who Gained Health Insurance Coverage Under the ACA, and Where Do They Live?. Urban Institute. December 2016.

Monheit, AC, Cantor JC, DeLia D, Belloff D. How Have State Policies to Expand Dependent Coverage Affected the Health Insurance Status of Young Adults. Health Services Research. 2011; 46(1): 251-267.

National Research Council, Institute of Medicine and Transportation Research Board. Preventing Teen Motor Crashes: Contributions from the Behavioral and Social Sciences: Workshop Report. 2007. National Academies Press. Washington, D.C.

Sommers BD, Buchmueller T, Decker SL, Carey C, Kronick R. The Affordable Care Act Has Led to Significant Gains in Health Insurance and Access to Care for Young Adults. Health Aff (Millwoood). 2013; 32(1):165-174.

United States Department of Labor. Young Adults and the Affordable Care Act: Protecting Young Adults and Eliminating Burdens on Businesses and Families. http://www.dol.gov/ebsa/faqs/faq-dependentcoverage.html. Accessed November 14, 2013. 
Figure I: Health Insurance Coverage in 2008 and 2013, by Age

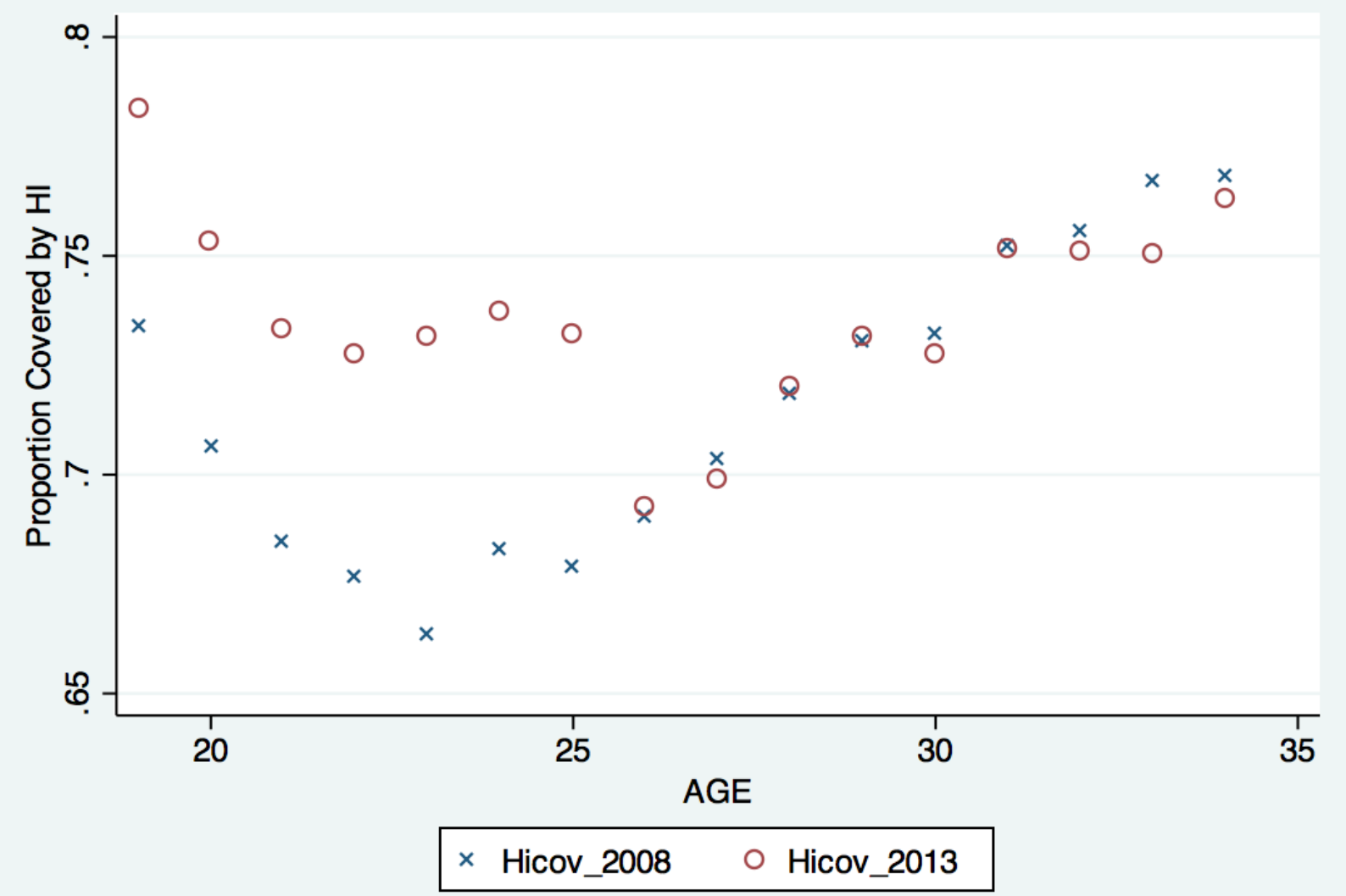

Data: American Community Survey 2008, 2013 
Figure II: Percent Change in BI Claim Counts from 2007 to 2012, by Claimant Age

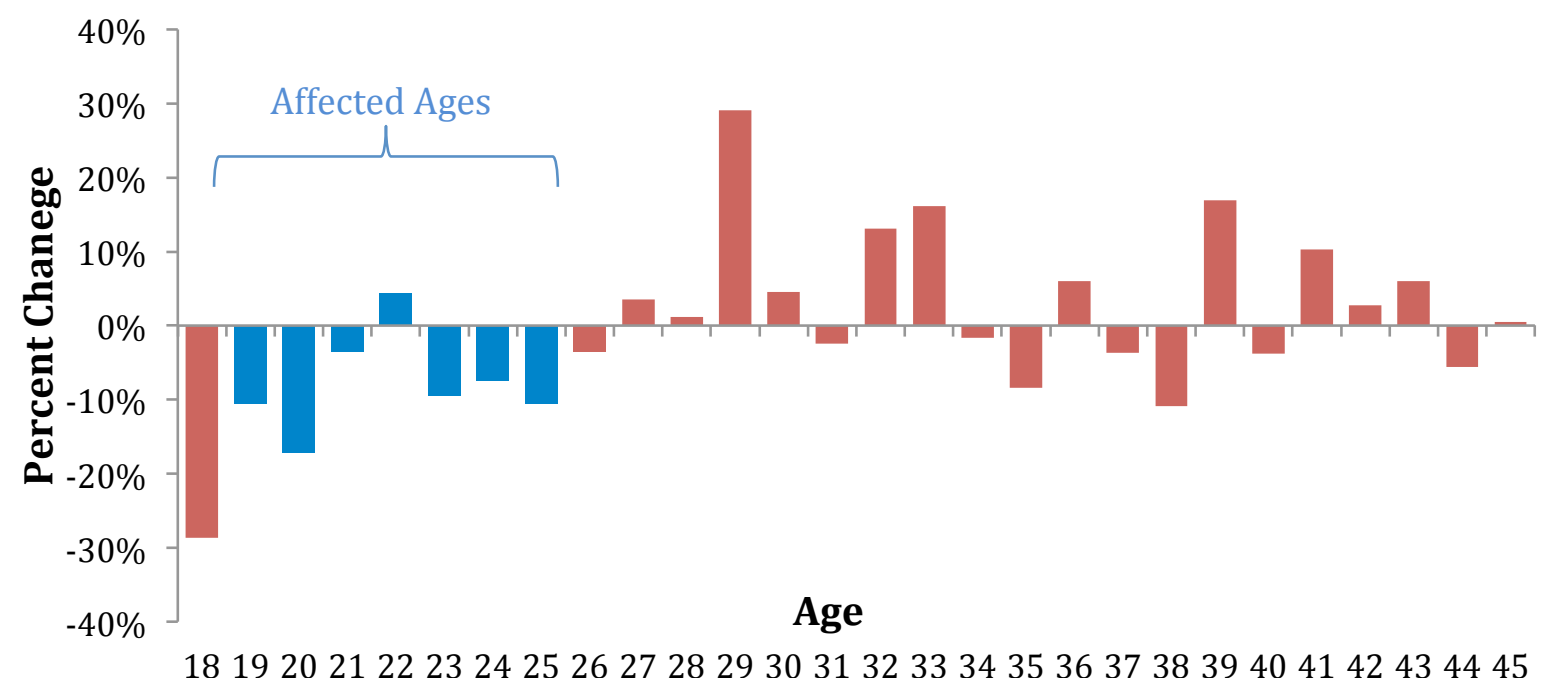

Figure III: Percent Change in PIP Claim Counts from 2017 to 2012, by Claimant Age

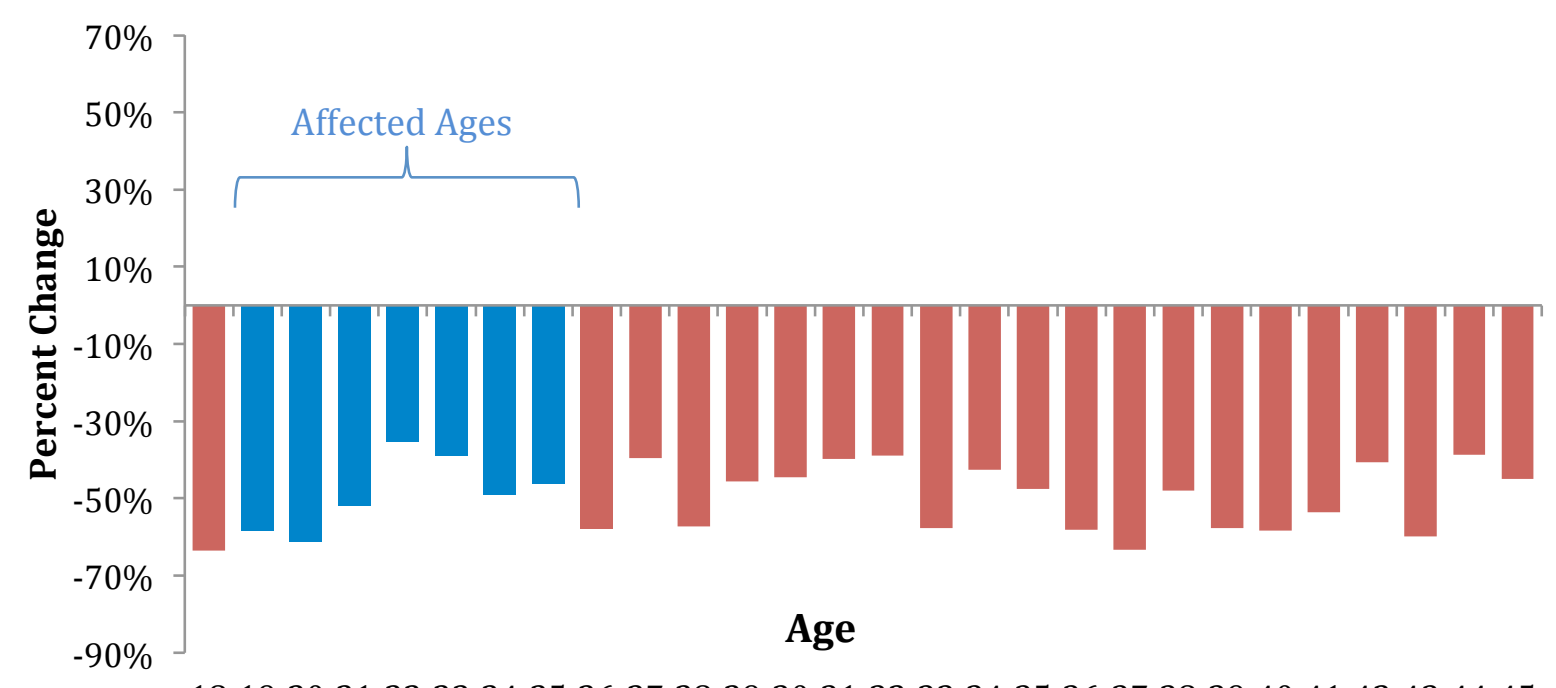


Figure IV: Percent Change in the Mean BI Medical Damage Amount (per Closed Claim) from 2007 to 2012, by Claimant Age

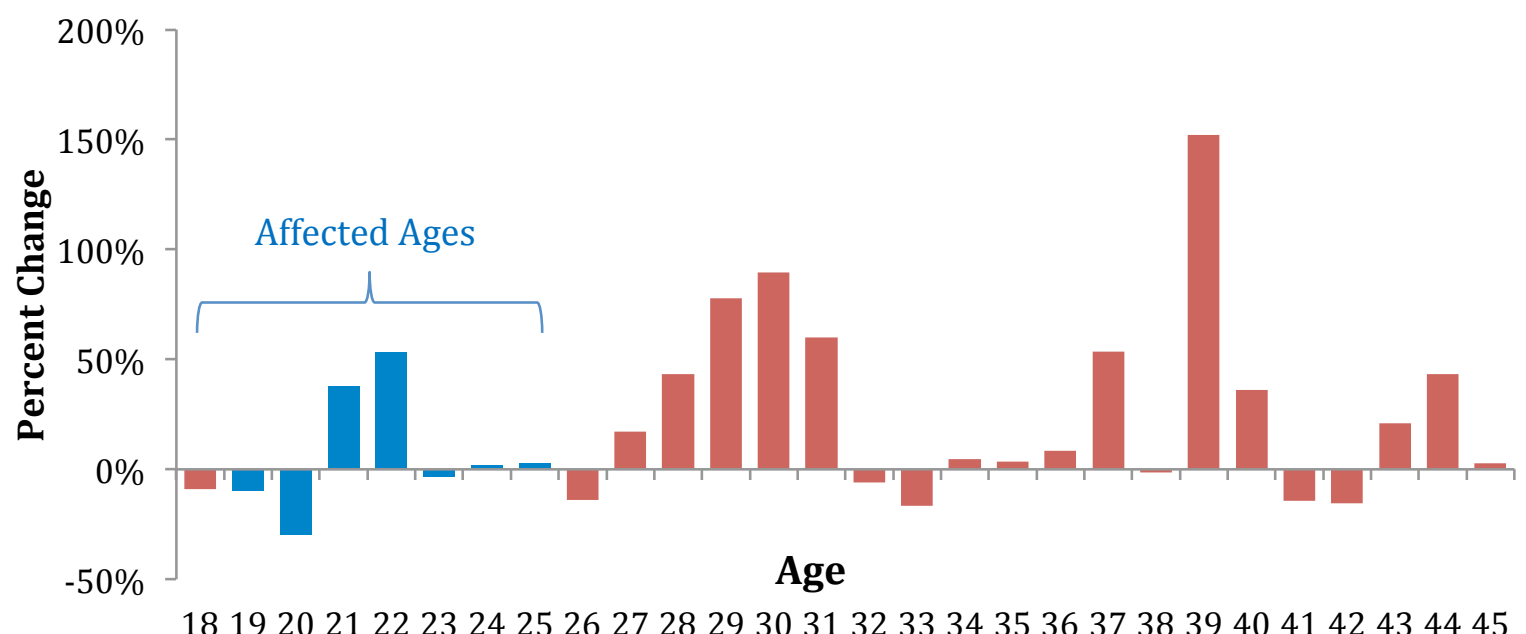

Figure V: Percent Change in the Mean BI Medical Paid Amount (per Closed Claim) from 2007 to 2012, by Claimant Age

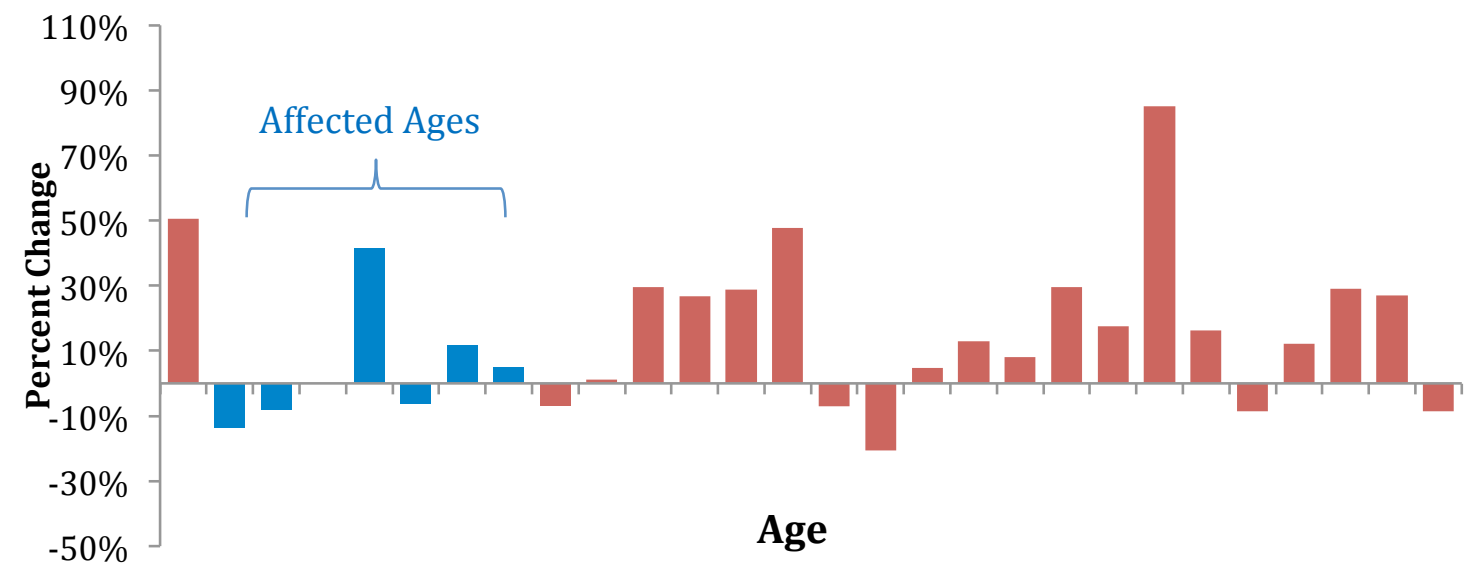

18192021222324252627282930313233343536373839404142434445 
Figure VI: Percent Change in the Mean BI Total Paid Amount (per Closed Claim) from 2007 to 2012, by Claimant Age

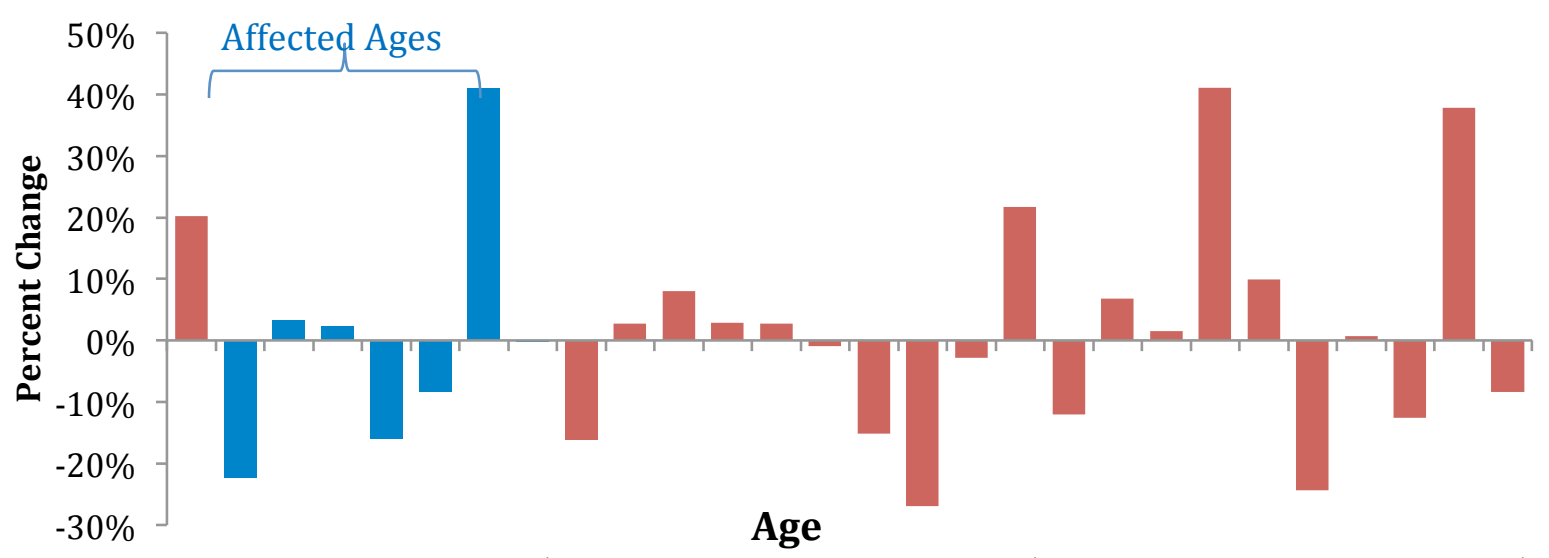

Figure VII: Percent Change in the Mean PIP Medical Damage Amount (per Closed Claim) from 2007 to 2012, by Claimant Age

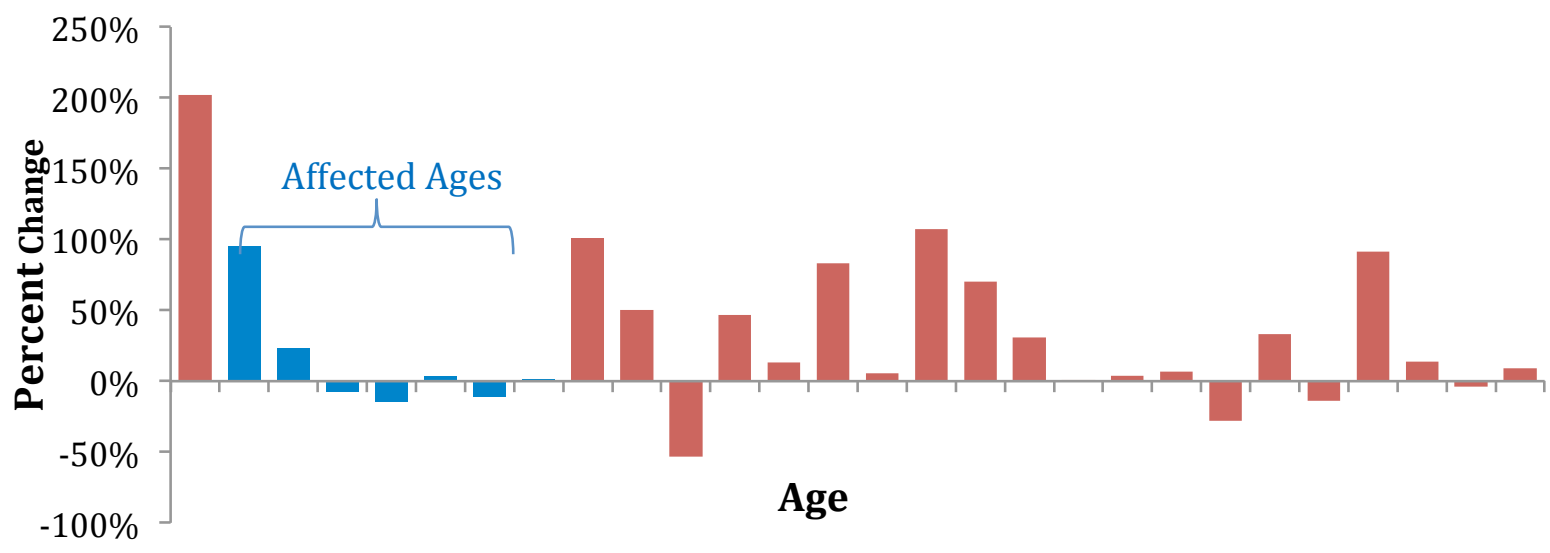

18192021222324252627282930313233343536373839404142434445 
Figure VIII: Percent Change in the Mean PIP Medical Paid Amount (per Closed Claim) from 2007 to 2012, by Claimant Age

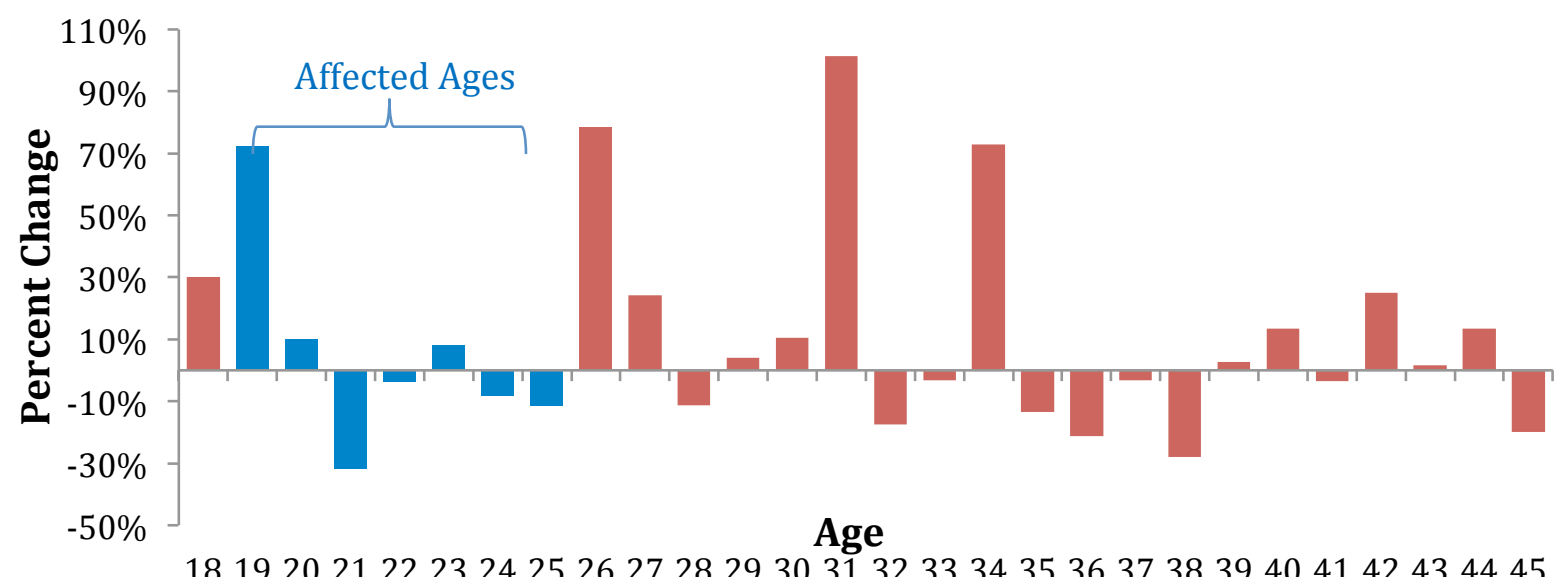

Figure IX: Percent Change in the Mean PIP Total Paid Amount (per Closed Claim) from 2007 to 2012, by Claimant Age

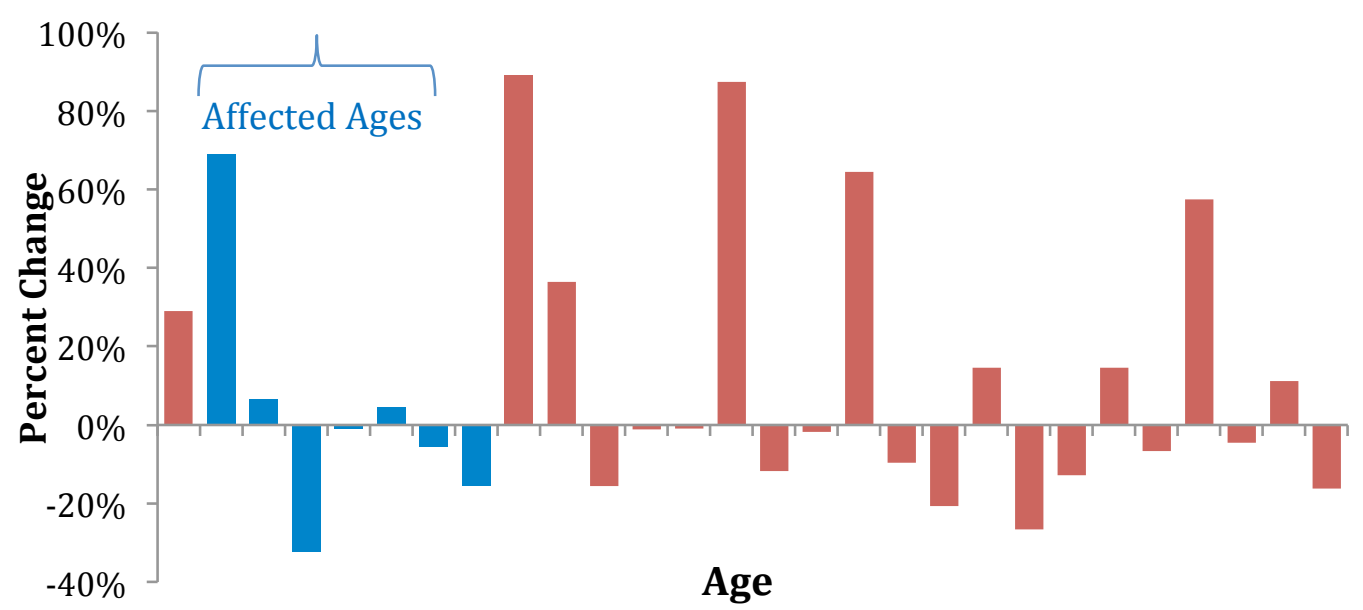

18192021222324252627282930313233343536373839404142434445 
Table I: BI and PIP Claims Count Analyses (Ages 19-34)

\section{BI Claims Count}

Treated Age Group * Post_Policy

Age, Time, State and State Time Fixed Effects

Demographic Controls

$\mathrm{N}$
$-.126 * * *$

(.036)

PIP Claims Count

(1)

.006

(.079)
(1)

BI Claims Count

(2)

$-.107^{* *}$

(.036)

PIP Claims Count

(2)

.072

$(.085)$

$\begin{array}{cc}\text { Yes } & \text { Yes } \\ \text { No } & \text { Yes } \\ 1632 & 1632\end{array}$

Notes: ${ }^{* * *}$ Statistically significant at $<=1 \% . * *$ Statistically significant at $<=5 \%$ *Statistically significant at $<=10 \%$ level. Estimates are from Poisson regression models. Standard errors are in parantheses and clustered on age. Demographic controls include adjustments for education, employment, average wages, number of vehicles and marital status. 
Table II: BI Medical Damage, Medical Paid and Total Paid Amounts (Ages 19-34)

\begin{tabular}{|c|c|c|c|}
\hline & $\begin{array}{l}\text { Medical Damage } \\
\text { (1) }\end{array}$ & $\begin{array}{c}\text { Medical Damage } \\
\text { (2) }\end{array}$ & $\begin{array}{c}\text { Medical Damage } \\
\text { (3) }\end{array}$ \\
\hline \multirow[t]{2}{*}{ Treated Age Group * Post_Policy } & -.047 & -.062 & -.06 \\
\hline & $(.061)$ & $(.055)$ & $(.05)$ \\
\hline \multirow[t]{2}{*}{$\mathrm{N}$} & 9106 & 9106 & 9106 \\
\hline & $\begin{array}{l}\text { Medical Paid } \\
\text { (1) }\end{array}$ & $\begin{array}{l}\text { Medical Paid } \\
\text { (2) }\end{array}$ & $\begin{array}{l}\text { Medical Paid } \\
\text { (3) }\end{array}$ \\
\hline \multirow[t]{2}{*}{ Treated Age Group * Post_Policy } & .008 & -.016 & -.014 \\
\hline & $(.066)$ & $(.054)$ & $(.053)$ \\
\hline \multirow[t]{2}{*}{$\mathrm{N}$} & 7903 & 7903 & 7903 \\
\hline & $\begin{array}{l}\text { Total Paid } \\
\text { (1) }\end{array}$ & $\begin{array}{l}\text { Total Paid } \\
\text { (2) }\end{array}$ & $\begin{array}{l}\text { Total Paid } \\
\text { (3) }\end{array}$ \\
\hline \multirow[t]{2}{*}{ Treated Age Group * Post_Policy } & $-.072 *$ & $-0.090 * *$ & $-0.093 * *$ \\
\hline & $(.038)$ & $(.037)$ & $(.036)$ \\
\hline $\mathrm{N}$ & 10539 & 10539 & 10539 \\
\hline Age, Time, State and State Time Fixed Effects & Yes & Yes & Yes \\
\hline Injury and Accident Severity Controls & No & Yes & Yes \\
\hline Claimant and Policy Controls & No & No & Yes \\
\hline
\end{tabular}

Notes: $* * *$ Statistically significant at $<=1 \%$. ${ }^{*}$ Statistically significant at $<=5 \%$ *Statistically significant

at $<=10 \%$. Estimates are from OLS regression models with $L N(Y)$ as the dependent variable. Standard errors are in parantheses and clustered on age. All regression models include dummy variables for age, accident year, accident state and accident state*accident year interactions. Injury controls include a full set of dummy variables for all injuries reported in the data and dummy variables for injury severity, impact severity and disability status. Claimant and policy characteristic control variables include dummy varibles for claimant sex, claimant location, employee work status, policy limits, determination of fault, and the number of vehicles involved in the accident. 
Table III: PIP Medical Damage, Medical Paid and Total Paid Amounts (Ages 19-34)

\begin{tabular}{|c|c|c|c|}
\hline & $\begin{array}{l}\text { Medical Damage } \\
\text { (1) }\end{array}$ & $\begin{array}{l}\text { Medical Damage } \\
\text { (2) }\end{array}$ & $\begin{array}{c}\text { Medical Damage } \\
\text { (3) }\end{array}$ \\
\hline \multirow[t]{2}{*}{ Treated Age Group * Post_Policy } & -.036 & .001 & -.006 \\
\hline & $(.122)$ & $(.096)$ & $(.096)$ \\
\hline \multirow[t]{3}{*}{$\mathrm{N}$} & 3487 & 3487 & 3487 \\
\hline & Medical Paid & Medical Paid & Medical Paid \\
\hline & (1) & (2) & (3) \\
\hline \multirow[t]{2}{*}{ Treated Age Group * Post_Policy } & -.035 & -.005 & -.007 \\
\hline & $(.134)$ & $(.113)$ & $(.112)$ \\
\hline \multirow[t]{2}{*}{$\mathrm{N}$} & 3435 & 3435 & 3435 \\
\hline & $\begin{array}{l}\text { Total Paid } \\
\text { (1) }\end{array}$ & $\begin{array}{l}\text { Total Paid } \\
\text { (2) }\end{array}$ & $\begin{array}{l}\text { Total Paid } \\
\text { (3) }\end{array}$ \\
\hline \multirow[t]{2}{*}{ Treated Age Group * Post_Policy } & -.029 & -.011 & -.013 \\
\hline & $(.13)$ & $(.110)$ & $(.109)$ \\
\hline $\mathrm{N}$ & 3575 & 3575 & 3575 \\
\hline Age, Time, State and State Time Fixed Effects & Yes & Yes & Yes \\
\hline Injury and Accident Severity Controls & No & Yes & Yes \\
\hline Claimant and Policy Controls & No & No & Yes \\
\hline
\end{tabular}

Notes: *** Statistically significant at $<=1 \%$. ** Statistically significant at $<=5 \%$ *Statistically significant at $<=10 \%$. Estimates are from OLS regression models with $L N(Y)$ as the dependent variable. Standard errors are in parantheses and clustered on age. All regression models include dummy variables for age, accident year, accident state and accident state*accident year interactions. Injury controls include a full set of dummy variables for all injuries reported in the data and dummy variables for injury severity, impact severity and disability status. Claimant and policy characteristic control variables include dummy varibles for claimant sex, claimant location, employee work status, policy limits, determination of fault, and the number of vehicles involved in the accident. 
Table IV: BI and PIP Claims Count Analyses (Ages 23-28)

\section{BI Claims Count}

(1)

Treated Age Group * Post_Policy
$-.115 * * *$

(.026)

PIP Claims Count

(1)

.15

(.11)

Yes

No

612

\section{BI Claims Count}

(2)

$-.100 * * *$

(.025)

PIP Claims Count

(2)

.17

(.13)

Yes

Yes

612

Notes: $* * *$ Statistically significant at $<=1 \%$. ${ }^{* *}$ Statistically significant at $<=5 \%$ $*$ Statistically significant at $<=10 \%$ level. Estimates are from Poisson regression models. Standard errors are in parantheses and clustered on age. Demographic controls include adjustments for education, employment, average wages, number of vehicles and marital status. 
Table V: BI Medical Damage, Medical Paid and Total Paid Amounts (Ages 23-28)

\begin{tabular}{|c|c|c|c|}
\hline & $\begin{array}{l}\text { Medical Damage } \\
\text { (1) }\end{array}$ & $\begin{array}{l}\text { Medical Damage } \\
\text { (2) }\end{array}$ & $\begin{array}{l}\text { Medical Damage } \\
\text { (3) }\end{array}$ \\
\hline \multirow[t]{2}{*}{ Treated Age Group * Post_Policy } & -.129 & $-.15 * *$ & $-.137 *$ \\
\hline & $(.068)$ & $(.048)$ & $(.051)$ \\
\hline \multirow[t]{3}{*}{$\mathrm{N}$} & 3552 & 3552 & 3552 \\
\hline & Medical Paid & Medical Paid & Medical Paid \\
\hline & (1) & (2) & (3) \\
\hline \multirow[t]{2}{*}{ Treated Age Group *Post_Policy } & -.137 & $-.13^{*}$ & -.119 \\
\hline & $(.066)$ & $(.053)$ & $(.056)$ \\
\hline \multirow[t]{2}{*}{$\mathrm{N}$} & 3088 & 3088 & 3088 \\
\hline & $\begin{array}{l}\text { Total Paid } \\
\text { (1) }\end{array}$ & $\begin{array}{l}\text { Total Paid } \\
\text { (2) }\end{array}$ & $\begin{array}{l}\text { Total Paid } \\
\text { (3) }\end{array}$ \\
\hline \multirow[t]{2}{*}{ Treated Age Group * Post_Policy } & -.116 & $-0.158 * *$ & $-0.162 * *$ \\
\hline & $(.069)$ & $(.050)$ & $(.050)$ \\
\hline$N$ & 4080 & 4080 & 4080 \\
\hline Age, Time, State and State Time Fixed Effects & Yes & Yes & Yes \\
\hline Injury and Accident Severity Controls & No & Yes & Yes \\
\hline Claimant and Policy Controls & No & No & Yes \\
\hline
\end{tabular}

Notes: ***Statistically significant at $<=1 \%$. ** Statistically significant at $<=5 \%$ *Statistically significant at $<=10 \%$. Estimates are from OLS regression models with $L N(Y)$ as the dependent variable. Standard errors are in parantheses and clustered on age. All regression models include dummy variables for age, accident year, accident state and accident state*accident year interactions. Injury controls include a full set of dummy variables for all injuries reported in the data and dummy variables for injury severity, impact severity and disability status. Claimant and policy characteristic control variables include dummy varibles for claimant sex, claimant location, employee work status, policy limits, determination of fault, and the number of vehicles involved in the accident. 
Table VI: PIP Medical Damage, Medical Paid and Total Paid Amounts (Ages 23-28)

\begin{tabular}{|c|c|c|c|}
\hline & $\begin{array}{l}\text { Medical Damage } \\
\text { (1) }\end{array}$ & $\begin{array}{c}\text { Medical Damage } \\
\text { (2) }\end{array}$ & $\begin{array}{c}\text { Medical Damage } \\
\text { (3) }\end{array}$ \\
\hline \multirow[t]{2}{*}{ Treated Age Group * Post_Policy } & -.09 & -.013 & .031 \\
\hline & $(.16)$ & $(.125)$ & $(.137)$ \\
\hline \multirow[t]{2}{*}{$\mathrm{N}$} & 1307 & 1307 & 1307 \\
\hline & $\begin{array}{c}\text { Medical Paid } \\
\text { (1) }\end{array}$ & $\begin{array}{l}\text { Medical Paid } \\
\text { (2) }\end{array}$ & $\begin{array}{c}\text { Medical Paid } \\
\text { (3) }\end{array}$ \\
\hline \multirow[t]{2}{*}{ Treated Age Group * Post_Policy } & -.057 & -.015 & .024 \\
\hline & $(.186)$ & $(.136)$ & $(.149)$ \\
\hline \multirow[t]{2}{*}{$\mathrm{N}$} & 1285 & 1285 & 1285 \\
\hline & $\begin{array}{l}\text { Total Paid } \\
\text { (1) }\end{array}$ & $\begin{array}{l}\text { Total Paid } \\
\text { (2) }\end{array}$ & $\begin{array}{l}\text { Total Paid } \\
\text { (3) }\end{array}$ \\
\hline \multirow[t]{2}{*}{ Treated Age Group * Post_Policy } & -.117 & -.065 & -.036 \\
\hline & $(.193)$ & $(.151)$ & $(.172)$ \\
\hline $\mathrm{N}$ & 1338 & 1338 & 1338 \\
\hline Age, Time, State and State Time Fixed Effects & Yes & Yes & Yes \\
\hline Injury and Accident Severity Controls & No & Yes & Yes \\
\hline Claimant and Policy Controls & No & No & Yes \\
\hline
\end{tabular}

Notes: $* *$ Statistically significant at $<=1 \% . * *$ Statistically significant at $<=5 \%$ *Statistically significant

at $<=10 \%$. Estimates are from OLS regression models with $L N(Y)$ as the dependent variable. Standard errors are in parantheses and clustered on age. All regression models include dummy variables for age, accident year, accident state and accident state*accident year interactions. Injury controls include a full set of dummy variables for all injuries reported in the data and dummy variables for injury severity, impact severity and disability status. Claimant and policy characteristic control variables include dummy varibles for claimant sex, claimant location, employee work status, policy limits, determination of fault, and the number of vehicles involved in the accident. 
Table VII: BI Charges Analyses (Ages 19-34 and Ages 23-28)

\section{Ages 19-34}

Treated Age Group * Post_Policy

N

AGES 23-28

Treated Age Group * Post_Policy

Age, Time, State and State Time Fixed Effects

Injury and Accident Severity Controls

Claimant and Policy Controls
Hospital Charges

(1)

(.063)

5047

Hospital Char
$\begin{gathered}(\mathbf{1}) \\ -.049 \\ (.032)\end{gathered}$

(1)

(.032)

1977

Yes

Yes
ER Physician Charges

(2)
-.098

$-.098$

$(.067)$

3634

ER Physician Charges
(2)
$-.186^{* * *}$
$(.067)$

Chiropractor Charges

(.093)

1408

Yes

Yes

Yes

(3)

1452

GP Charges

(4)

$(.064)$

3654

2396

GP Charges

(4)

899

Yes

Yes

Yes
X-ray Charges

(5)

4120

Statistically significant at $<=1 \%$. * Statistically significant at $<=5 \% *$ Statistically significant

at $<=10 \%$. Estimates are from OLS regression models with $\mathrm{LN}(\mathrm{Y})$ as the dependent variable. Standard errors

are in parantheses and clustered on age. All regression models include dummy variables for age, accident year,

accident state and accident state*accident year interactions. Injury controls include a full set of dummy variables for all injuries reported in the data and dummy variables for injury severity, impact severity and disability status.

Claimant and policy characteristic control variables include dummy varibles for claimant sex, claimant location,

employee work status, policy limits, determination of fault, and the number of vehicles involved in the accident. 